Article

\title{
Fast Preparation of Porous MnO/C Microspheres as Anode Materials for Lithium-Ion Batteries
}

\author{
Jing Su ${ }^{1,2,3}$, Hao Liang ${ }^{1}$, Xian-Nian Gong ${ }^{1}$, Xiao-Yan Lv ${ }^{4}$, Yun-Fei Long ${ }^{1}$ and \\ Yan-Xuan Wen 1,2,3,* \\ 1 School of Chemistry and Chemical Engineering, Guangxi University, Nanning 530004, China; \\ sujing928@126.com (J.S.); 15253732337@163.com (H.L.); 138786083682050@163.com (X.-N.G.); \\ longyf@gxu.edu.cn (Y.-F.L.) \\ 2 Guangxi Colleges and Universities Key Laboratory of Novel Energy Materials and Related Technology, \\ Nanning 530004, China \\ 3 Guangxi Novel Battery Materials Research Center of Engineering Technology, Nanning 530004, China \\ 4 The New Rural Development Research Institute, Guangxi University, Nanning 530004, China; \\ lvxiaoyan666@163.com \\ * Correspondence: wenyanxuan@vip.163.com; Tel./Fax: +86-771-323-3718
}

Academic Editor: Thomas Nann

Received: 27 February 2017; Accepted: 24 May 2017; Published: 26 May 2017

\begin{abstract}
Porous $\mathrm{MnO} / \mathrm{C}$ microspheres have been successfully fabricated by a fast co-precipitation method in a T-shaped microchannel reactor. The structures, compositions, and electrochemical performances of the obtained $\mathrm{MnO} / \mathrm{C}$ microspheres are characterized by X-ray diffraction, field emission scanning electron microscopy (FE-SEM), transmission electron microscopy (HRTEM), Brunauer-Emmett-Teller analysis, charge-discharge testing, cyclic voltammograms, and electrochemical impedance spectra. Experimental results reveal that the as-prepared $\mathrm{MnO} / \mathrm{C}$, with a specific surface area of $96.66 \mathrm{~m}^{2} \cdot \mathrm{g}^{-1}$ and average pore size of $24.37 \mathrm{~nm}$, exhibits excellent electrochemical performance, with a discharge capacity of $655.4 \mathrm{mAh} \cdot \mathrm{g}^{-1}$ after cycling 50 times at $1 \mathrm{C}$ and capacities of $808.3,743.7,642.6,450.1$, and $803.1 \mathrm{mAh} \cdot \mathrm{g}^{-1}$ at $0.2,0.5,1,2$, and $0.2 \mathrm{C}$, respectively. Moreover, the controlled method of using a microchannel reactor, which can produce larger specific surface area porous $\mathrm{MnO} / \mathrm{C}$ with improved cycling performance by shortening lithium-ion diffusion distances, can be easily applied in real production on a large scale.
\end{abstract}

Keywords: lithium-ion batteries; anode materials; $\mathrm{MnO}$; Co-precipitation; T-shaped microchannel reactor

\section{Introduction}

In the past few decades, rechargeable lithium-ion batteries (LIBs) have attracted considerable attention as a major power source for portable electronic devices and electric vehicles [1-3]. However, the commercial anode material, graphite, cannot easily meet the increasing demand for large energy and power densities, with a limited theoretical capacity of $372 \mathrm{mAh} \cdot \mathrm{g}^{-1}[4,5]$. Transition metal oxides have attracted significant research attention due to their two- or threefold improvement in reversible capacity, compared with that of graphite [6-8]. Among all of the kinds of transition metal oxides investigated for LIBs, manganese oxide $(\mathrm{MnO})$ has received particular interest because of its high theoretical capacity $\left(755 \mathrm{mAh} \cdot \mathrm{g}^{-1}\right)$, relatively low electromotive force $\left(1.032 \mathrm{~V} \mathrm{vs} . \mathrm{Li}^{+} / \mathrm{Li}\right)$, high density $\left(5.43 \mathrm{~g} \cdot \mathrm{cm}^{-3}\right)$, environmental friendliness, and abundance in nature [9-11]. However, poor cycling stability and rate capability, owing to the low conductivity and large volume changes during Li-ion insertion/extraction, have hampered the application of $\mathrm{MnO}[12,13]$. Many strategies have been adopted to overcome these shortcomings, such as downsizing the particle size [14,15], designing new 
morphologies [16,17], doping [18-22], carbon coating [23-27], and constructing hollow or porous structures [28-33].

Among all of these strategies, structuring porous $\mathrm{MnO}$ electrodes has been an effective strategy for enhancing the capacity retention by reversibly accommodating large volume changes. Additionally, the pores of the porous electrode provide good access for the electrolyte to the electrode surface. The large surface areas of the porous structures also facilitate charge transfer across the electrode/electrolyte interfaces [34].

Porous $\mathrm{MnO}$ materials can be synthesized by templated or non-templated methods, such as co-precipitation [35], hydrothermal, solvothermal [36], sol-gel, and deposition processes [37]. Among these synthesis methods, the co-precipitation method is simpler than the abovementioned processes and is suitable for large-scale production in commercial fields. Zhong et al. [35] synthesized porous $\mathrm{MnO} / \mathrm{C}$ microspheres, which delivered a reversible capacity of $600 \mathrm{mAh} \cdot \mathrm{g}^{-1}$ at a rate of $400 \mathrm{~mA} \cdot \mathrm{g}^{-1}$. These porous $\mathrm{MnO}$ particles were obtained with $\mathrm{MnCO}_{3}$ as the precursor through a co-precipitation method, and carbon was coated by chemical vapor deposition. However, the particle size and distribution from the co-precipitation method always depended on the mass transfer and dispersion in the reactor. In traditional co-precipitation, solutions are mixed by stirring for several hours $[9,35]$, which does not easily control particle nucleation-growth processes. The micro-mixing intensity and mass transfer for the co-precipitation process need to be improved.

In this article, a novel and simple method for the fast synthesis of porous $\mathrm{MnO} / \mathrm{C}$ microspheres with large specific areas is demonstrated for the first time. $\mathrm{MnCO}_{3}$ precursor was prepared in a T-shaped microchannel reactor in only a few seconds. Due to the enhancement of the mixing effect in the microchannel reactor, the calcinated production, $\mathrm{MnO} / \mathrm{C}$ microspheres had a narrow size distribution and porous structure. These morphological and structural characteristics improved the electrochemical performance of $\mathrm{MnO} / \mathrm{C}$ anodes [38,39].

\section{Experimental}

\subsection{Preparation of Materials}

Porous $\mathrm{MnO} / \mathrm{C}$ was prepared as follows: Two solutions of $\mathrm{MnSO}_{4} \cdot \mathrm{H}_{2} \mathrm{O}\left(0.1 \mathrm{~mol} \cdot \mathrm{L}^{-1}\right)$ and $\mathrm{NH}_{4} \mathrm{HCO}_{3}\left(0.2 \mathrm{~mol} \cdot \mathrm{L}^{-1}\right)$ were simultaneously injected into the T-shaped microchannel reactor with an accurate syringe pump (2PB00C, Beijing Xingda Technology Co., Ltd., Beijing, China) at the same fixed flow rate of $50 \mathrm{~mL} \cdot \mathrm{min}^{-1}$ to generate the crystal $\mathrm{MnCO}_{3}$ (Figure 1a). The reaction mechanism of the $\mathrm{MnCO}_{3}$ preparation was as follows: $\mathrm{MnSO}_{4}+2 \mathrm{NH}_{4} \mathrm{HCO}_{3} \rightarrow \mathrm{MnCO}_{3} \downarrow+\left(\mathrm{NH}_{4}\right)_{2} \mathrm{SO}_{4}+\mathrm{CO}_{2} \uparrow+\mathrm{H}_{2} \mathrm{O}$.

Following this co-precipitation process, the product was collected by filtration, the sulfate ions were washed out (with the washing water tested with a $0.5 \mathrm{~mol} \cdot \mathrm{L}^{-1} \mathrm{BaCl}_{2}$ solution), and dried in a vacuum oven at $60^{\circ} \mathrm{C}$. After that, the synthesized $\mathrm{MnCO}_{3}$ precursor was mixed with sucrose at a mass ratio of $10: 3$ by ultrasonication and dried at $60^{\circ} \mathrm{C}$. Finally, the composite was calcined in a tube furnace at $450{ }^{\circ} \mathrm{C}$ in $\mathrm{N}_{2}$ for $6 \mathrm{~h}$ to obtain porous $\mathrm{MnO} / \mathrm{C}$. During this calcination process, the $\mathrm{MnCO}_{3}$ precursor translated to $\mathrm{MnO}$, and the $\mathrm{CO}_{2}$ gas released $\mathrm{MnCO}_{3} \rightarrow \mathrm{MnO}+\mathrm{CO}_{2} \uparrow$.

The sketch of the T-shaped microchannel reactor is depicted in Figure 1b. The microchannel reactor has a mixing channel length of $50 \mathrm{~mm}$, a width of $0.8 \mathrm{~mm}$, and a depth of $0.2 \mathrm{~mm}$, while each inlet channel has a width of $0.4 \mathrm{~mm}$ and a length of $10 \mathrm{~mm}$. During the experiments, two opposite feed streams, $\mathrm{MnSO}_{4}$ and $\mathrm{NH}_{4} \mathrm{HCO}_{3}$ solutions, were mixed at the crunode, where the reactants impinge, then flowed through the vertical channel as the reaction proceeds. 

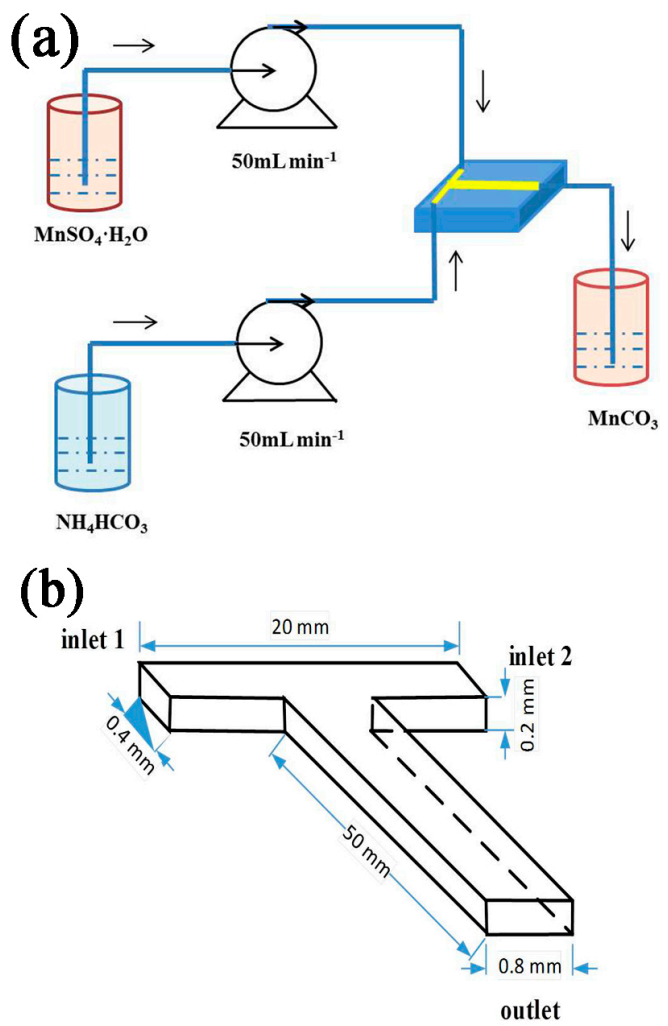

Figure 1. The experimental setup for the preparation of $\mathrm{MnCO}_{3}(\mathbf{a})$ and the sketch of the T-shaped microchannel reactor $(\mathbf{b})$.

\subsection{Characterization of Materials}

The crystalline structure and phase information of the as-prepared products were determined by X-ray powder diffraction (XRD) on an X' Pert PRO X-ray diffractometer (D8 Advance, Bruker-AXS, Karlsruhe, Germany) with $\mathrm{Cu} \mathrm{K} \alpha$ radiation $(V=40 \mathrm{KV}, I=40 \mathrm{~mA}$ and $\lambda=0.15406 \mathrm{~nm})$ in the range of $10-80^{\circ}$. The morphology and particle sizes of the resultant samples were characterized with a field emission scanning electron microscope (FE-SEM, S-3400, Hitachi, Tokyo, Japan) and a transmission electron microscope (FE-TEM, Tecnai G2 F20, FEI, Hillsboro, OR, USA). The nitrogen adsorption-desorption isotherms were measured on a V-Sorb 2800 series analyzer (Gold APP Instruments, Beijing, China) to calculate the specific area by the Brunauer-Emmett-Teller (BET) analysis method and the pore size distribution by the Barrett-Joyner-Halenda method. The carbon content in the final product was tested using a Flash2000 elemental analyzer (Thermo Fisher Scientific, Waltham, MA, USA).

\subsection{Electrochemical Measurements}

The electrochemical performance of $\mathrm{MnO} / \mathrm{C}$ was tested using CR2032 coin-type half cells. The working electrode was produced by mixing $\mathrm{MnO} / \mathrm{C}$, acetylene black, and a lithium polyacrylate (Li-PAA) binder [40] in a weight ratio of 8:1:1 in distilled water to form a homogenous slurry. The slurry mixture was coated on a copper foil substrate, followed by drying at $120^{\circ} \mathrm{C}$ in a vacuum oven for $12 \mathrm{~h}$. The loading of the active material in electrode plate is approximately 60 to $70 \mathrm{mg} \cdot \mathrm{cm}^{-2}$. To set up the charge/discharge current and calculate the special capacity, the amount of loading of every electrode was weighted accurately. Half Li-ion battery cells were assembled in a glove-box filled with a dry and high-purity argon atmosphere. The coins use lithium metal foils as the counter/reference electrode, a Celgard 2300 as the separator, and $1 \mathrm{~mol} \cdot \mathrm{L}^{-1} \mathrm{LiPF}_{6}$ (dissolved in ethylene carbonate and dimethyl carbonate with a volume ratio of 1:1) as the electrolyte. The galvanostatic charge and discharge 
measurements of the cells were evaluated on a NEWARE BTS Serier battery cycler (Neware, Shenzhen, Guangdong, China) at different current densities in a voltage range from 0.01 to $3 \mathrm{~V}$ with a precision of $0.05 \%$. The charge/discharge current density and the specific capacity were calculated based on the whole weight of $\mathrm{MnO} / \mathrm{C}$ in the electrode, where a $1 \mathrm{C}$ rate was $755 \mathrm{mAh} \cdot \mathrm{g}^{-1}$. Cyclic voltammogram (CV) measurements were conducted on a PCI 4750 electrochemical workstation (Gamry, Warminster, $\mathrm{PA}, \mathrm{USA}$ ) with a scan rate of $0.1 \mathrm{mV} \cdot \mathrm{s}^{-1}$ and potential windows ranging from 0.01 to $3 \mathrm{~V}$ (versus $\mathrm{Li} / \mathrm{Li}^{+}$). Electrochemical impedance spectroscopy (EIS) was completed using a Gamry PCI-4750 electrochemical workstation (Gamry, Warminster, PA, USA) in a frequency range from $100 \mathrm{kHz}$ to $1 \mathrm{mHz}$.

\section{Results and Discussion}

\subsection{Characterization of Samples}

The XRD patterns of the $\mathrm{MnCO}_{3}$ precursor are shown in Figure 2a. All diffraction peaks agree perfectly with the rhombohedral $\mathrm{MnCO}_{3}$ structure (JCPDS 44-1472), and no other phases were detected, indicating that the high-purity $\mathrm{MnCO}_{3}$ precursor had been prepared by the T-type microchannel reactor. The XRD characteristic peaks of the pure phase $\mathrm{MnO}$ and $\mathrm{MnO} / \mathrm{C}$ composites are presented in Figure $2 \mathrm{~b}$. All of the peaks of the products were coincident with the standard XRD pattern of cubic $\mathrm{MnO}$ (JCPDS 75-0626), and no impure diffraction peaks were observed, confirming that $\mathrm{MnCO}_{3}$ had been completely decomposed into $\mathrm{MnO}$ without the generation of any other substance, and the carbon layer formed on the $\mathrm{MnO}$ surface was amorphous. The lattice constants of the $\mathrm{MnO} / \mathrm{C}$ phase were calculated as $a=b=c=4.434(1) \AA, V=87.18 \AA$, and $\alpha=\beta=\gamma=90^{\circ}$, which coincided well with the literature [41-43].
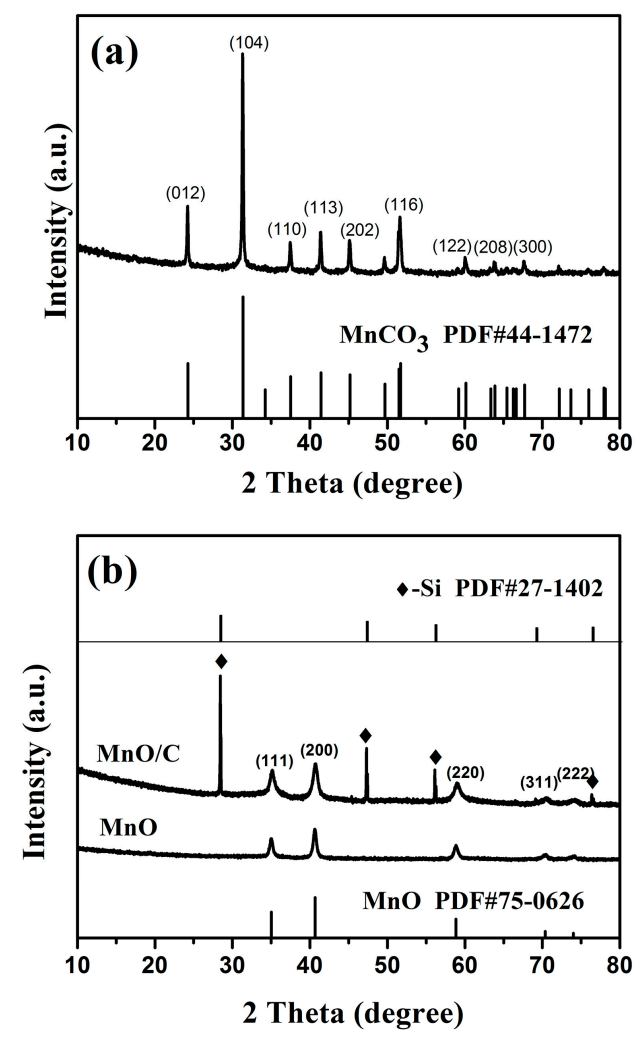

Figure 2. $\mathrm{XRD}$ patterns of $\mathrm{MnCO}_{3}$ precursor (a) and the calcined $\mathrm{MnCO}_{3}$ (b) (the top is the $\mathrm{MnO} / \mathrm{C}$ sample; the bottom is the $\mathrm{MnO}$ sample). 
Figure 3a-c present the SEM images of the prepared $\mathrm{MnCO}_{3}$ microspheres with approximate sizes distributions of 2-3 $\mu \mathrm{m}$, and the surface of the microspheres consist of flake-like particles with a thickness of about $50 \mathrm{~nm}$. Compared to $\mathrm{MnCO}_{3}$ prepared in bulk batch reactors [35], our microchannel reactor can develop $\mathrm{MnCO}_{3}$ with a smaller mean particle size mainly due to a better mixing effect and improved mass transfer performance in the microfluidic device [44]. The Reynolds number for the feed channel was 2781 when the flow rate was $50 \mathrm{~mL} \cdot \mathrm{min}^{-1}\left(\mathrm{H}_{2} \mathrm{O}\right.$ in $10{ }^{\circ} \mathrm{C}$ was used as the flow media), which is much larger than the 1110 that was reported for a similar microchannel reactor [45]. The impinging of liquid with a high velocity and a large Reynolds number at the T-junction induced a high intensity vortex, which led to the efficient micro-mixing and preparation of the $\mathrm{MnCO}_{3}$ microspheres.
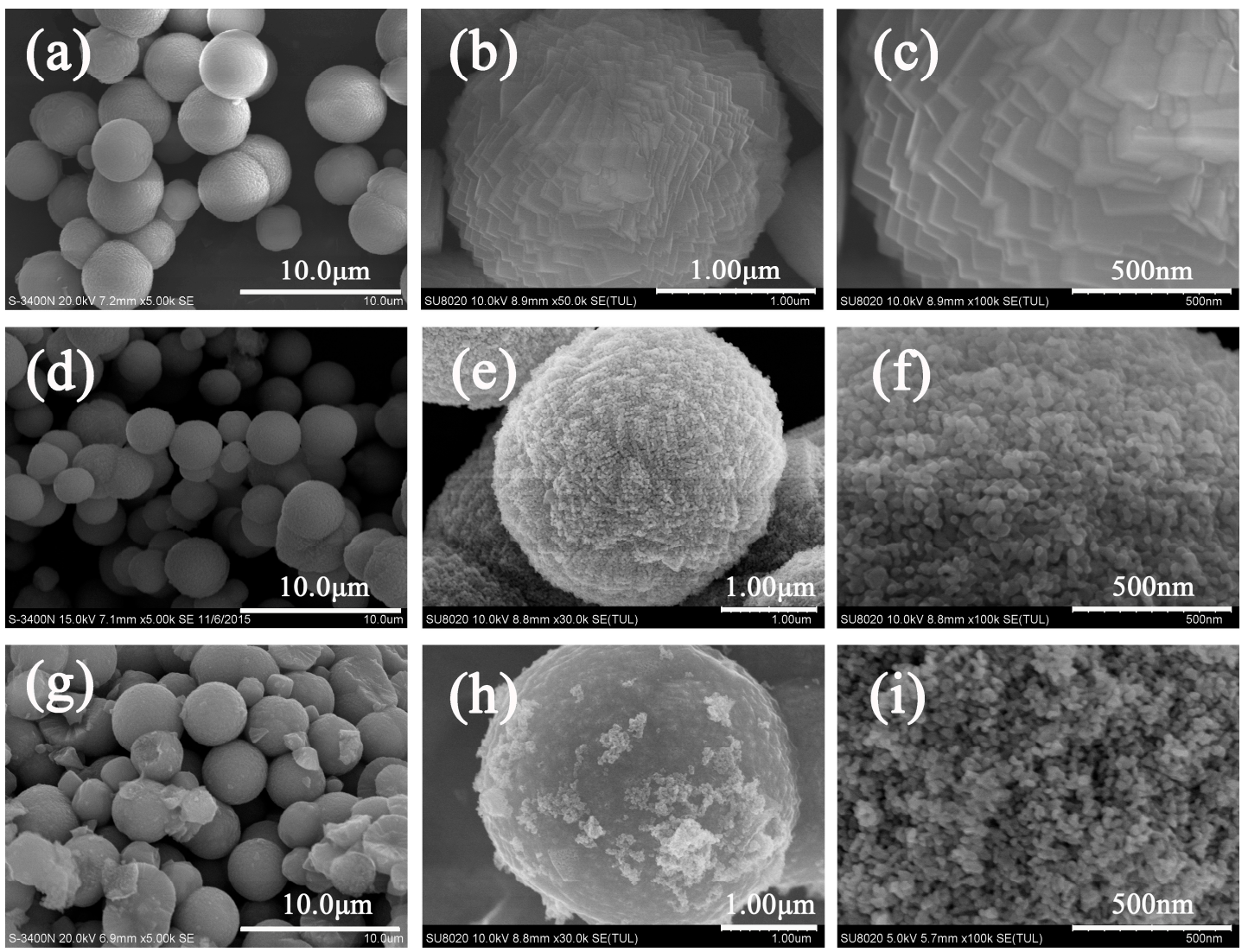

Figure 3. FE-SEM images of $\mathrm{MnCO}_{3}(\mathbf{a}-\mathbf{c}), \mathrm{MnO}(\mathbf{d}-\mathbf{f})$, and $\mathrm{MnO} / \mathrm{C}(\mathbf{g}-\mathbf{i})$.

The SEM images in Figure 3d,g demonstrated the morphological characteristics of $\mathrm{MnO}$ and $\mathrm{MnO} / \mathrm{C}$, with no apparent variations of the spherical structure during the calcination process. Figure 3e,f,h,i show that the surface of $\mathrm{MnO} / \mathrm{C}$ is glossier than $\mathrm{MnO}$, on account of the formation of the carbon stratum. For the inner morphology of $\mathrm{MnO}$, the microspheres were composed of loosely packed primary particles with diameters of about $50 \mathrm{~nm}$ and tiny porous structures that were generated by $\mathrm{CO}_{2}$ release during calcination. However, the emancipating $\mathrm{CO}_{2}$ also caused a volume expansion that led to an increase in the particle sizes of $\mathrm{MnO}$ and $\mathrm{MnO} / \mathrm{C}$, which had proximate diameters of 3-4 $\mu \mathrm{m}$.

The FE-TEM images of the $\mathrm{MnO} / \mathrm{C}$ microspheres are exhibited in Figure 4a. The prepared $\mathrm{MnO} / \mathrm{C}$ microspheres were composed of nano-sized grains, and the voids between the nanoparticles form a porous framework. The HRTEM image in Figure $4 \mathrm{~b}$ shows a continuous and uniform carbon layer (about 3-4 nm) along the $\mathrm{MnO}$ surface and the carbon content of the final sample was $21.9 \pm 0.3 \%$. This clearly demonstrated that the lattice fringe spacing is about $0.25 \mathrm{~nm}$, corresponding to the cubic MnO XRD results for the (111) crystal plane. 


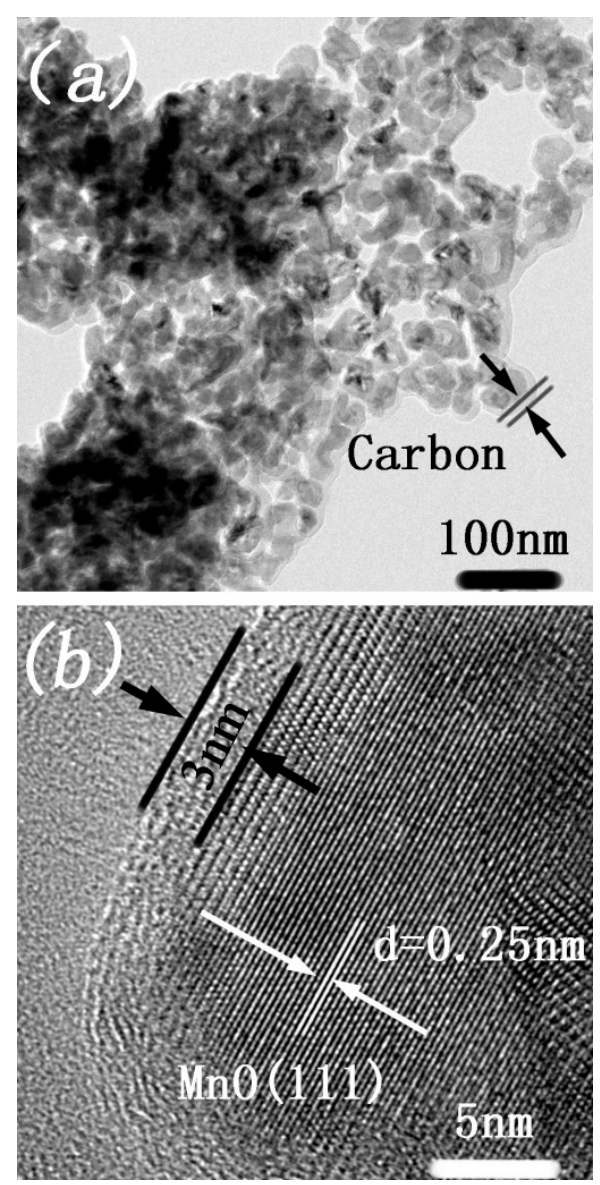

Figure 4. FE-TEM images of $\mathrm{MnO} / \mathrm{C}$ microspheres (a) and the carbon layer (b).

The BET specific surface areas and porous structures of $\mathrm{MnCO}_{3}$ and $\mathrm{MnO} / \mathrm{C}$ were further measured by nitrogen adsorption-desorption isotherms. Figure 5 shows the isotherms and pore size distribution of the two specimens. The isotherm of $\mathrm{MnCO}_{3}$ exhibits type IV isotherm behavior with obvious $\mathrm{H} 2$ hysteresis loops and $\mathrm{MnO} / \mathrm{C}$ displays typical IV isotherms with $\mathrm{H} 3$ hysteresis loops, both of the samples confirm the presence of mesopores. From the inset of Figure 5a, the average pore size of $\mathrm{MnCO}_{3}$ is $2.22 \pm 0.01 \mathrm{~nm}$ and the BET surface area is measured to be $38.06 \mathrm{~m}^{2} \cdot \mathrm{g}^{-1}$ with a standard deviation of $1 \%$. The corresponding pore size distribution of $\mathrm{MnO} / \mathrm{C}$ is clarified in the inset of Figure $5 b$, with an average pore size of $24.37 \pm 0.01 \mathrm{~nm}$ in diameter, in accordance with the FE-SEM and TEM images, and a BET specific surface area of $96.66 \mathrm{~m}^{2} \cdot \mathrm{g}^{-1}$. The BET surface area and the pore size of $\mathrm{MnO} / \mathrm{C}$ are larger than $\mathrm{MnCO}_{3}$ is mainly attributed to the release of $\mathrm{CO}_{2}$ during the decomposition of $\mathrm{MnCO}_{3}$. In addition, such a porous structure, with a specific surface area higher than that found in previous studies $[31,41,46,47]$, can not only accelerate the diffusion of $\mathrm{Li}^{+}$between the electrolyte and internal active materials but also buffer the volume variation during $\mathrm{Li}^{+}$insertion/extraction to promote the reversible capacity and the stability of the cycling performance $[34,46,48]$. 

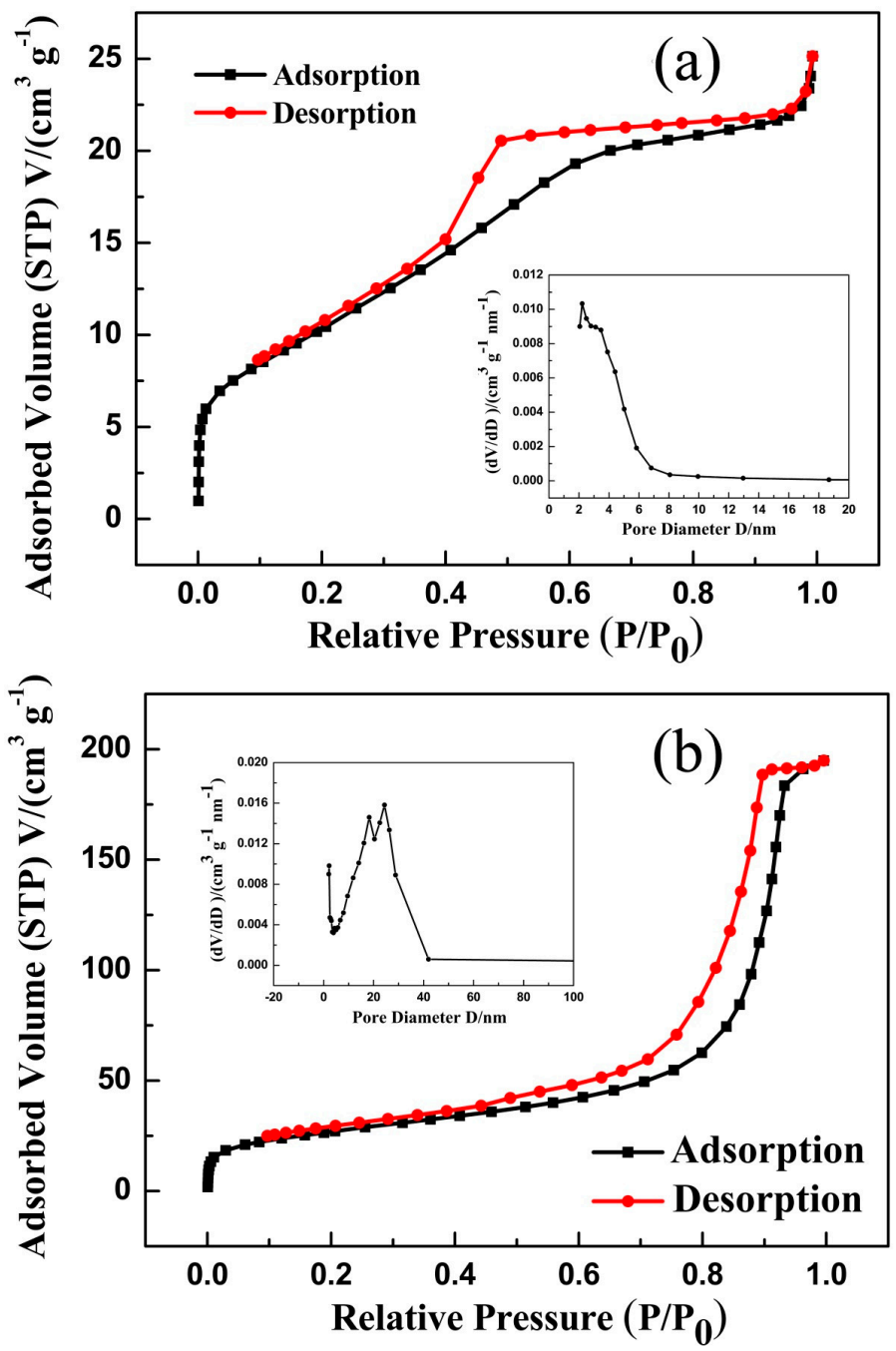

Figure 5. Nitrogen adsorption-desorption isotherms of $\mathrm{MnCO}_{3}(\mathbf{a})$ and $\mathrm{MnO} / \mathrm{C}(\mathbf{b})$. The insets show the two samples of the pore-size distributions.

\subsection{Electrochemical Performance of the $\mathrm{MnO} / \mathrm{C}$ Electrode}

To examine the electrochemical storage properties of the as-prepared porous $\mathrm{MnO} / \mathrm{C}$ material, galvanostatic discharge-charge cycling was firstly explored, as shown in Figure 6. The initial and second discharge-specific capacities of the $\mathrm{MnO} / \mathrm{C}$ sample at $1 \mathrm{C}\left(755 \mathrm{~mA} \cdot \mathrm{g}^{-1}\right)$ were 1282.3 and $694.4 \mathrm{mAh} \cdot \mathrm{g}^{-1}$, respectively. The first discharge capacity was much higher than the theoretical value $\left(755 \mathrm{mAh} \cdot \mathrm{g}^{-1}\right)$. The irreversible capacity loss in the first cycle was mainly attributed to the formation of the solid electrolyte interface (SEI) layer and, to a certain extent, decomposition of the electrolyte $[33,36,49,50]$. However, from the second cycle, the $\mathrm{MnO} / \mathrm{C}$ electrodes exhibit excellent cycling performance, accompanied with coulombic efficiency, which was maintained at almost $100 \%$. The first discharge voltage plateau at $0.1 \mathrm{~V}$ in Figure 6a corresponded to the initial reduction of $\mathrm{MnO}$ to $\mathrm{Mn}$ and the formation of the SEI layer [23,33,51], then the discharge plateau turned to $0.3 \mathrm{~V}$ in the subsequent cycles, indicating the irreversible phase transformation, owing to the formation of $\mathrm{Li}_{2} \mathrm{O}$ and metallic $\mathrm{Mn}[7,33,47,52]$. The charge curves show no voltage plateau, but a slope from 1.0 to $1.5 \mathrm{~V}$, suggesting the oxidation of $\mathrm{Mn}$ to $\mathrm{MnO}[13,15,47]$. From Figure $6 \mathrm{~b}$, we discover that the electrolyte decomposition did not happen from the second cycle, and the discharge-specific capacity after 50 cycles can still be retained as high as $654.8 \mathrm{mAh} \cdot \mathrm{g}^{-1}$ with a capacity retention rate of $98 \%$, 
except for the initial two cycles, thus exhibiting excellent electrochemical properties compared with the $\mathrm{MnO} / \mathrm{C}$ prepared by the traditional co-precipitation method [22,35].
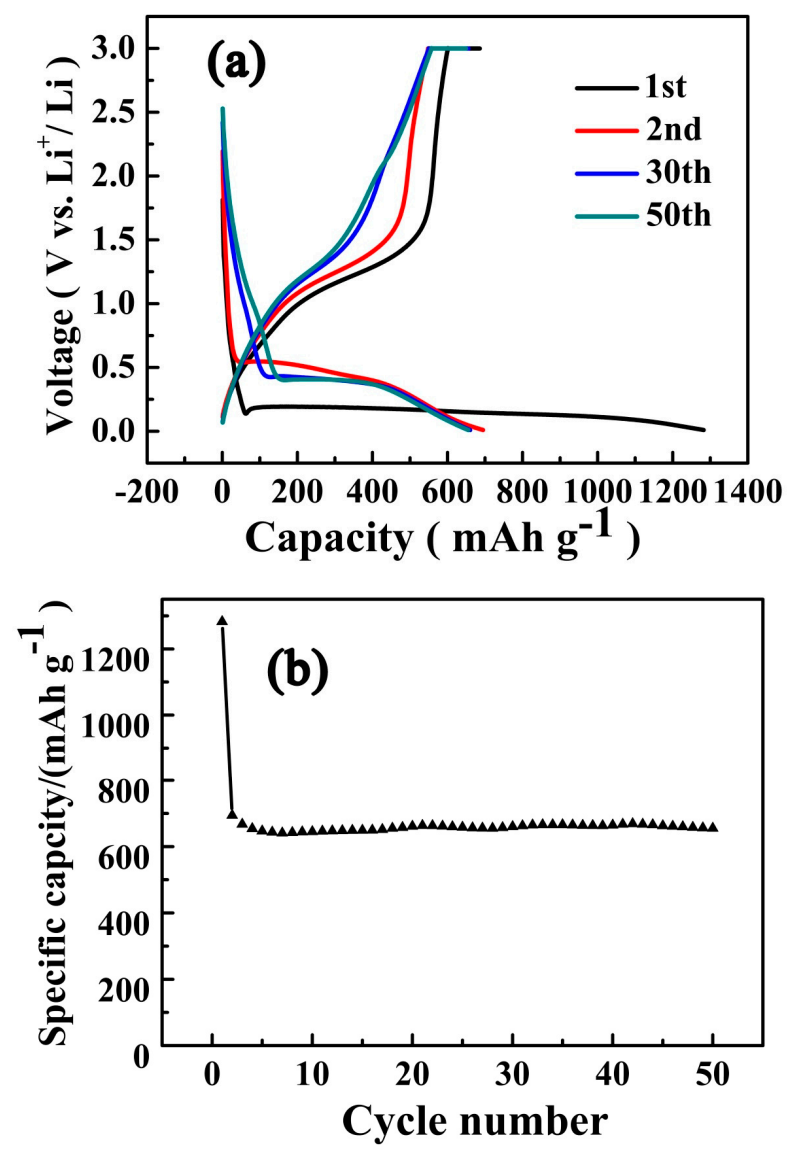

Figure 6. Charge-discharge curves (a) and cycling performance (b) of the prepared $\mathrm{MnO} / \mathrm{C}$ sample at a rate of $1 \mathrm{C}$.

The rate capacities of the porous $\mathrm{MnO} / \mathrm{C}$ microspheres at various current densities are exhibited in Figure 7. The corresponding discharge capacities reach 808.3, 743.7, 642.6, 450.1, and 803.1 $\mathrm{mAh} \cdot \mathrm{g}^{-1}$ at $0.2,0.5,1,2$, and $0.2 \mathrm{C}$, respectively. It is worth noting that when the current density was decreased back to $0.2 \mathrm{C}$, the discharge capacity of $803.1 \mathrm{mAh} \cdot \mathrm{g}^{-1}$ was almost $100 \%$ recovered, illustrating the excellent rate capability. The outstanding electrochemical performance of $\mathrm{MnO} / \mathrm{C}$ might be attributed to the porous structure with a high specific surface area and the carbon coating, which can effectively accommodate the stress and strain of the volume change and hinder the agglomeration and separation of $\mathrm{MnO}$ during the Li-ion insertion/extraction process [33]. In comparison with the traditional co-precipitation method $[9,22-24,30,35]$, our method not only presents a sample with remarkable specific capacity, significant cycling stability, and excellent rate performance, but also shortens the reaction time, strengthens the mixing effect, and makes it easy to control the reaction process. Clearly, these results indicate that our T-shaped microchannel reactor method is a very promising method for synthesizing high-performance $\mathrm{MnO} / \mathrm{C}$ and related materials. 


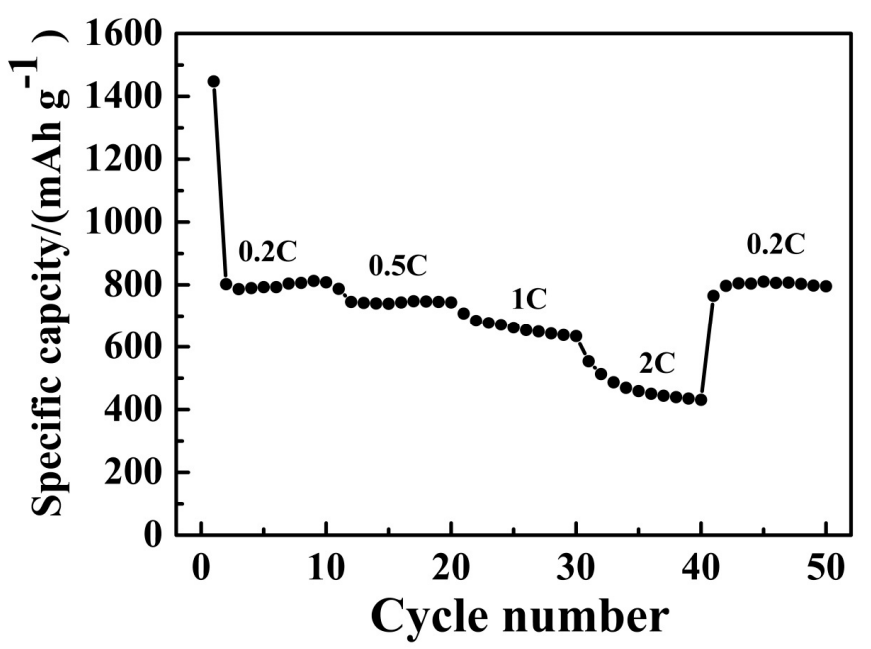

Figure 7. Rate performances of the porous $\mathrm{MnO} / \mathrm{C}$ at various current rates.

The $\mathrm{CV}$ curves of the porous $\mathrm{MnO} / \mathrm{C}$ composite electrode in a voltage range from $0.01-3.0 \mathrm{~V}$ with a scan rate of $0.1 \mathrm{mV} \cdot \mathrm{s}^{-1}$ for the first four cycles are shown in Figure 8. The CV curve for $\mathrm{Cu}$ current collector, which is without any oxidation or reduction peak in the above voltage range is also shown in this figure. In the first cathodic sweep for $\mathrm{MnO} / \mathrm{C}$ composite electrode, only one sharp reduction peak close to $0.1 \mathrm{~V}$ is observed, agreeing well with the shaping of the SEI layers and the reduction of $\mathrm{Mn}^{2+}$ to $\mathrm{Mn}^{0}$. From the second cycle onwards, the main reduction current peak turns to $0.3 \mathrm{~V}$, suggesting the formation of $\mathrm{Li}_{2} \mathrm{O}$ and metallic $\mathrm{Mn}$, presented as $\mathrm{MnO}+2 \mathrm{Li} \rightarrow \mathrm{Mn}^{0}+\mathrm{Li}_{2} \mathrm{O}$, which is an irreversible phase transformation $[3,28]$. In the oxidation half cycle, a wide main peak is observed at $1.3 \mathrm{~V}$, in good accord with the oxidation of $\mathrm{Mn}^{0}$ to $\mathrm{Mn}^{2+}$ and the decomposition of $\mathrm{Li}_{2} \mathrm{O}[30,37,53]$. Both the reduction and oxidation curves in the subsequent cycles overlap well, demonstrating the excellent reversibility of the electrochemical reaction, which matches well with the charge/discharge experiments.

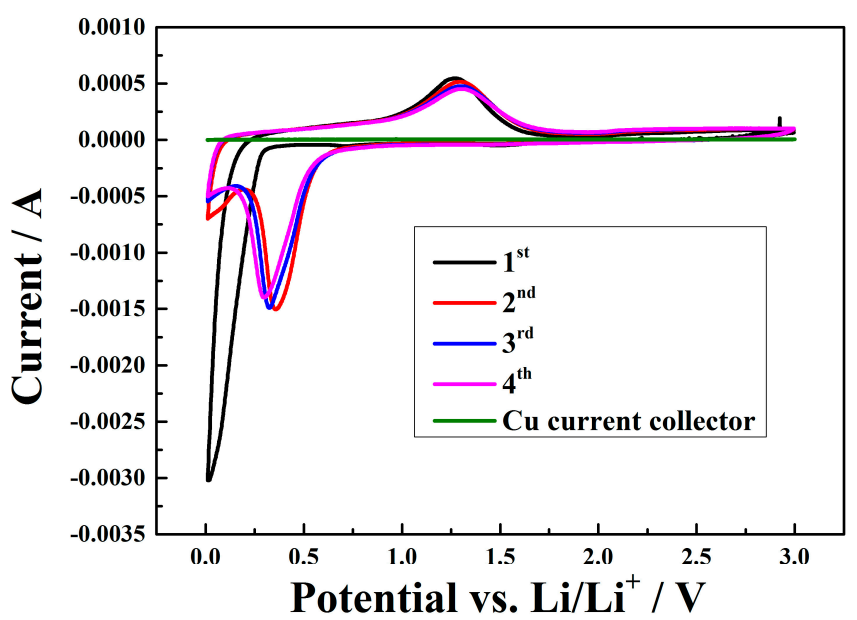

Figure 8. $\mathrm{CV}$ curves of the porous $\mathrm{MnO} / \mathrm{C}$ and $\mathrm{Cu}$ current collector at a scan rate of $0.1 \mathrm{mV} \cdot \mathrm{s}^{-1}$.

EIS was further executed to explore the electrochemical characteristics of the electrode/electrolyte interface. Figure 9 shows the Nyquist plot of the $\mathrm{MnO} / \mathrm{C}$ electrode without any discharge/charge cycles, and the inset gives an equivalent circuit of the impedance spectra. The intercept of the high-frequency semicircle on the $Z^{\prime}$ axis is ascribed to the resistance of the electrolyte $\left(R_{s}\right)$. The high-frequency semicircle is associated with the capacitance $\left(C_{\text {sei }}\right)$ and the resistance $\left(R_{\text {sei }}\right)$ of the SEI layer. The middle-frequency semicircle is attributed to the charge transfer resistance $\left(R_{\mathrm{ct}}\right)$ between 
the electrodes. The straight line in the low frequency is consistent with Warburg impedance $\left(Z_{\mathrm{w}}\right)$, corresponding to the diffusion of Li-ions into the bulk electrode [33,42]. The fitting values of the kinetic parameters of the $\mathrm{MnO} / \mathrm{C}$ electrode are listed in Table 1 . It is worth noting that $R_{\mathrm{ct}}$ is much lower than that previously reported [13,22], indicating much higher reaction areas and a faster charge transfer at the electrode/electrolyte interface [9,33], which is attributed to the high surface area of the mesoporous structure and the carbon coating that facilitates the charge-transfer reaction. The diffusion coefficient of lithium ions $\left(D_{\mathrm{Li}}\right)$ in the $\mathrm{MnO} / \mathrm{C}$ sample is $3.64 \times 10^{-18} \mathrm{~cm}^{2} \cdot \mathrm{s}^{-1}$, which is larger than that reported by Yang et al. [18]. These results further illustrate that the porous $\mathrm{MnO} / \mathrm{C}$ microspheres should display excellent electrochemistry performance.

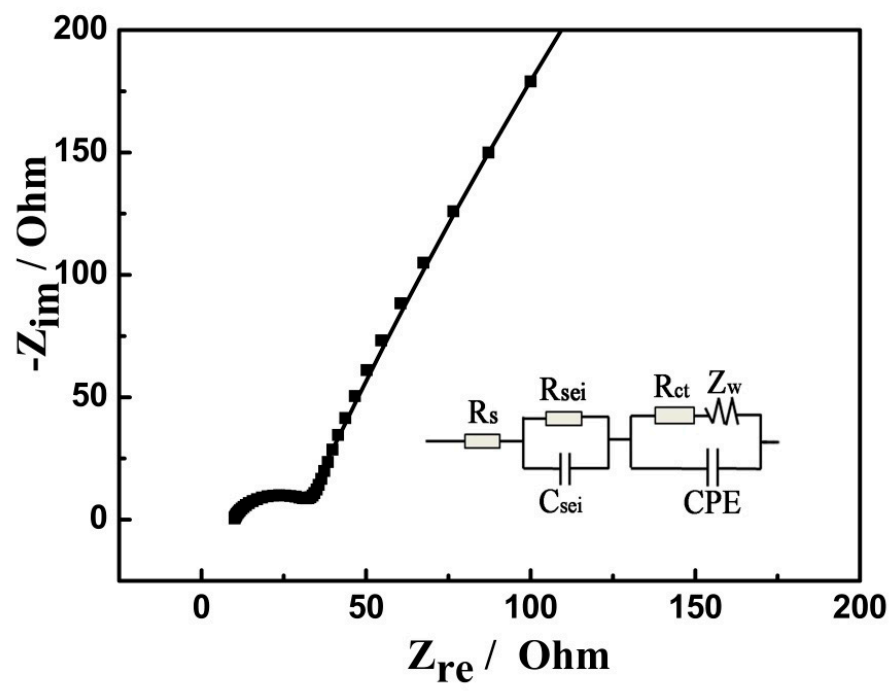

Figure 9. Impendence spectra for the prepared porous $\mathrm{MnO} / \mathrm{C}$.

Table 1. Simulation results of EIS in Figure 9.

\begin{tabular}{cccccc}
\hline$R_{\mathrm{s}} / \Omega$ & $C_{\mathrm{sei}} / \mathrm{F} \cdot \mathrm{cm}^{-2}$ & $R_{\mathrm{sei}} / \Omega$ & $\mathrm{CPE} Y_{\mathrm{o}} / \mathrm{S} \cdot \mathrm{s}^{\mathrm{n}} \cdot \mathrm{cm}^{-2}$ & $R_{\mathrm{ct}} / \Omega$ & $Z_{\mathrm{w}} / \mathrm{S} \cdot \mathrm{s}^{0.5} \cdot \mathrm{cm}^{-2}$ \\
\hline 3.88 & $6.45 \times 10^{-5}$ & 23.62 & $3.36 \times 10^{-4}$ & 16.32 & 0.00889 \\
\hline
\end{tabular}

\section{Conclusions}

In this work, we demonstrated a novel, economical, and facile strategy for fabricating porous $\mathrm{MnO} / \mathrm{C}$ microspheres by employing a T-shaped microchannel reactor. The resulting porous $\mathrm{MnO} / \mathrm{C}$ microspheres had an average pore size of $24.37 \mathrm{~nm}$ and a larger specific surface area of $96.66 \mathrm{~m}^{2} \cdot \mathrm{g}^{-1}$. As anode materials for Li-ion batteries, the prepared porous $\mathrm{MnO} / \mathrm{C}$ microspheres demonstrated electrochemical performance with a discharge capacity of $655.4 \mathrm{mAh} \cdot \mathrm{g}^{-1}$ at $1 \mathrm{C}$ after $50 \mathrm{cycles}$, which is mainly ascribed to the mesoporous structure and the carbon coating that stimulated Li-ion diffusion into the cathode by increasing the electrochemical reaction surface. The approach used in this work provides a fast, easily controllable, and mass-producible method of fabricating porous $\mathrm{MnO} / \mathrm{C}$ composites, and can dramatically save time and cost.

Acknowledgments: The authors appreciate the financial support from the National Natural Science Foundation of China (51564002, 21606055) and the Guangxi Postdoctoral Foundation.

Author Contributions: Jing Su and Hao Liang performed the experiments, analyzed the data, and drafted the manuscript. Xian-Nian Gong, Xiao-Yan Lv, and Yun-Fei Long contributed to the idea and discussion of the manuscript. Yan-Xuan Wen was the PI of this research and contributed to the idea, discussion, and writing of the final manuscript.

Conflicts of Interest: The authors declare no conflict of interest. 


\section{References}

1. Etacheri, V.; Marom, R.; Elazari, R.; Salitra, G.; Aurbach, D. Challenges in the development of advanced Li-ion batteries: A review. Energy Environ. Sci. 2011, 4, 3243-3262. [CrossRef]

2. Goodenough, J.B.; Park, K. The Li-Ion Rechargeable Battery: A Perspective. J. Am. Chem. Soc. 2013, 135, 1167-1176. [CrossRef] [PubMed]

3. Cho, J.S.; Hong, Y.J.; Kang, Y.C. Design and Synthesis of Bubble-Nanorod-Structured $\mathrm{Fe}_{2} \mathrm{O}_{3}-\mathrm{Carbon}$ Nanofibers as Advanced Anode Material for Li-Ion Batteries. ACS Nano 2015, 9, 4026-4035. [CrossRef] [PubMed]

4. Wang, J.; Zhang, C.; Kang, F. Nitrogen-Enriched Porous Carbon Coating for Manganese Oxide Nanostructures toward High-Performance Lithium-Ion Batteries. ACS Appl. Mater. Interfaces 2015, 7, 9185-9194. [CrossRef] [PubMed]

5. Wang, J.; Yang, Y.; Huang, Z.; Kang, F. MnO-carbon hybrid nanofiber composites as superior anode materials for lithium-ion batteries. Electrochim. Acta 2015, 170, 164-170. [CrossRef]

6. Lee, R.; Lin, Y.; Weng, Y.; Pan, H.; Lee, J.; Wu, N. Synthesis of high-performance $\mathrm{MnO}_{\mathrm{x}} /$ carbon composite as lithium-ion battery anode by a facile co-precipitation method: Effects of oxygen stoichiometry and carbon morphology. J. Power Sources 2014, 253, 373-380. [CrossRef]

7. Li, X.; Zhu, Y.; Zhang, X.; Liang, J.; Qian, Y. MnO@1-D carbon composites from the precursor $\mathrm{C}_{4} \mathrm{H}_{4} \mathrm{MnO}_{6}$ and their high-performance in lithium batteries. RSC Adv. 2013, 3, 10001-10006. [CrossRef]

8. Guo, J.; Liu, Q.; Wang, C.; Zachariah, M.R. Interdispersed Amorphous $\mathrm{MnO}_{\mathrm{x}}-$ Carbon Nanocomposites with Superior Electrochemical Performance as Lithium-Storage Material. Adv. Funct. Mater. 2012, 22, 803-811. [CrossRef]

9. Wang, S.; Xing, Y.; Xu, H.; Zhang, S. MnO Nanoparticles Interdispersed in 3D Porous Carbon Framework for High Performance Lithium-Ion Batteries. ACS Appl. Mater. Interfaces 2014, 6, 12713-12718. [CrossRef] [PubMed]

10. Qiao, H.; Yao, D.; Cai, Y.; Huang, F.; Wei, Q. One-pot synthesis and electrochemical property of MnO/C hybrid microspheres. Ionics 2013, 19, 595-600. [CrossRef]

11. Sun, Y.; Hu, X.; Luo, W.; Xia, F.; Huang, Y. Reconstruction of Conformal Nanoscale MnO on Graphene as a High-Capacity and Long-Life Anode Material for Lithium Ion Batteries. Adv. Funct. Mater. 2013, 23, 2436-2444. [CrossRef]

12. Zhang, S.; He, W.; Zhang, X.; Yang, X. Rational design of carbon-coated hollow MnO nanotubes for Li-ion batteries. J. Mater. Sci. Mater. Electron. 2015, 26, 2189-2197. [CrossRef]

13. Yang, C.; Gao, Q.; Tian, W.; Tan, Y.; Zhang, T.; Yang, K.; Zhu, L. Superlow load of nanosized MnO on a porous carbon matrix from wood fibre with superior lithium ion storage performance. J. Mater. Chem. A 2014, 2, 19975-19982. [CrossRef]

14. Liu, B.; Hu, X.; Xu, H.; Luo, W.; Sun, Y.; Huang, Y. Encapsulation of MnO Nanocrystals in Electrospun Carbon Nanofibers as High-Performance Anode Materials for Lithium-Ion Batteries. Sci. Rep. 2014, 4, 4229. [CrossRef] [PubMed]

15. Hu, H.; Cheng, H.; Liu, Z.; Yu, Y. Facile Synthesis of Carbon Spheres with Uniformly Dispersed MnO Nanoparticles for Lithium Ion Battery Anode. Electrochim. Acta 2015, 152, 44-52. [CrossRef]

16. Wang, S.; Ren, Y.; Liu, G.; Xing, Y.; Zhang, S. Peanut-like MnO@C core-shell composites as anode electrodes for high-performance lithium ion batteries. Nanoscale 2014, 6, 3508-3512. [CrossRef] [PubMed]

17. Zhang, X.; Xing, Z.; Wang, L.; Zhu, Y.; Li, Q.; Liang, J.; Yu, Y.; Huang, T.; Tang, K.; Qian, Y.; et al. Synthesis of $\mathrm{MnO} @ \mathrm{C}$ core-shell nanoplates with controllable shell thickness and their electrochemical performance for lithium-ion batteries. J. Mater. Chem. 2012, 22, 17864-17869. [CrossRef]

18. Chen, W.; Qie, L.; Shen, Y.; Sun, Y.; Yuan, L.; Hu, X.; Zhang, W.; Huang, Y. Superior lithium storage performance in nanoscaled $\mathrm{MnO}$ promoted by N-doped carbon webs. Nano Energy 2013, 2, 412-418. [CrossRef]

19. Gu, X.; Yue, J.; Chen, L.; Liu, S.; Xu, H.; Yang, J.; Qian, Y.; Zhao, X. Coaxial MnO/N-doped carbon nanorods for advanced lithium-ion battery anodes. J. Mater. Chem. A 2015, 3, 1037-1041. [CrossRef]

20. Masai, H.; Hino, Y.; Yanagida, T.; Fujimoto, Y. Photoluminescence and radioluminescence properties of MnO-doped SnO-ZnO-P $2 \mathrm{O}_{5}$ glasses. Opt. Mater. 2015, 42, 381-384. [CrossRef] 
21. Chen, R.; Yan, J.; Liu, Y.; Li, J. Three-Dimensional Nitrogen-Doped Graphene/MnO Nanoparticle Hybrids as a High-Performance Catalyst for Oxygen Reduction Reaction. J. Phys. Chem. C 2015, 119, 8032-8037. [CrossRef]

22. Sun, X.; Xu, Y.; Ding, P.; Chen, G.; Zheng, X.; Zhang, R.; Li, L. The composite sphere of manganese oxide and carbon nanotubes as a prospective anode material for lithium-ion batteries. J. Power Sources 2014, 255, 163-169. [CrossRef]

23. Mai, Y.J.; Zhang, D.; Qiao, Y.Q.; Gu, C.D.; Wang, X.L.; Tu, J.P. MnO/reduced graphene oxide sheet hybrid as an anode for Li-ion batteries with enhanced lithium storage performance. J. Power Sources 2012, 216, 201-207. [CrossRef]

24. Liu, Y.; Zhao, X.; Li, F.; Xia, D. Facile synthesis of MnO/C anode materials for lithium-ion batteries. Electrochim. Acta 2011, 56, 6448-6452. [CrossRef]

25. Su, L.; Zhong, Y.; Wei, J.; Zhou, Z. Preparation and electrochemical Li storage performance of MnO@C nanorods consisting of ultra small MnO nanocrystals. RSC Adv. 2013, 3, 9035-9041. [CrossRef]

26. Zhu, C.; Sheng, N.; Akiyama, T. MnO nanoparticles embedded in a carbon matrix for a high performance Li ion battery anode. RSC Adv. 2015, 5, 21066-21073. [CrossRef]

27. Jiang, H.; Hu, Y.; Guo, S.; Yan, C.; Lee, P.S.; Li, C. Rational Design of MnO/Carbon Nanopeapods with Internal Void Space for High-Rate and Long-Life Li-Ion Batteries. ACS Nano 2014, 8, 6038-6046. [CrossRef] [PubMed]

28. Li, X.; Li, D.; Qiao, L.; Wang, X.; Sun, X.; Wang, P.; He, D. Interconnected porous MnO nanoflakes for high-performance lithium ion battery anodes. J. Mater. Chem. 2012, 22, 9189-9194. [CrossRef]

29. Xu, G.; Xu, Y.; Sun, H.; Fu, F.; Zheng, X.; Huang, L.; Li, J.; Yang, S.; Sun, S. Facile synthesis of porous MnO/C nanotubes as a high capacity anode material for lithium ion batteries. Chem. Commun. 2012, 48, 8502-8504. [CrossRef] [PubMed]

30. Wang, X.; Qiu, S.; Lu, G.; He, C.; Liu, J.; Luan, L.; Liu, W. Fabrication of porous MnO microspheres with carbon coating for lithium ion battery application. CrystEngComm 2014, 16, 1802-1809. [CrossRef]

31. Li, X.; Shang, X.; Li, D.; Yue, H.; Wang, S.; Qiao, L.; He, D. Facile Synthesis of Porous MnO Microspheres for High-Performance Lithium-Ion Batteries. Part. Part. Syst. Charact. 2014, 31, 1001-1007. [CrossRef]

32. Yue, J.; Gu, X.; Chen, L.; Wang, N.; Jiang, X.; Xu, H.; Yang, J.; Qian, Y. General synthesis of hollow $\mathrm{MnO}_{2}$, $\mathrm{Mn}_{3} \mathrm{O}_{4}$ and $\mathrm{MnO}$ nanospheres as superior anode materials for lithium ion batteries. J. Mater. Chem. A 2014, 2, 17421-17426. [CrossRef]

33. Xia, Y.; Xiao, Z.; Dou, X.; Huang, H.; Lu, X.; Yan, R.; Gan, Y.; Zhu, W.; Tu, J.; Zhang, W.; et al. Green and Facile Fabrication of Hollow Porous MnO/C Microspheres from Microalgaes for Lithium-Ion Batteries. ACS Nano 2013, 7, 7083-7092. [CrossRef] [PubMed]

34. Anh, V.; Qian, Y.; Stein, A. Porous Electrode Materials for Lithium-Ion Batteries-How to Prepare Them and What Makes Them Special. Adv. Energy Mater. 2012, 2, 1056-1085.

35. Zhong, K.; Zhang, B.; Luo, S.; Wen, W.; Li, H.; Huang, X.; Chen, L. Investigation on porous MnO microsphere anode for lithium ion batteries. J. Power Sources 2011, 196, 6802-6808. [CrossRef]

36. Guo, S.; Lu, G.; Qiu, S.; Liu, J.; Wang, X.; He, C.; Wei, H.; Yan, X.; Guo, Z. Carbon-coated MnO microparticulate porous nanocomposites serving as anode materials with enhanced electrochemical performances. Nano Energy 2014, 9, 41-49. [CrossRef]

37. Ma, X.; Wan, Q.; Huang, X.; Ding, C.; Jin, Y.; Guan, Y.; Chen, C. Synthesis of three-dimensionally porous MnO thin films for lithium-ion batteries by improved Electrostatic Spray Deposition technique. Electrochim. Acta 2014, 121, 15-20. [CrossRef]

38. Liang, Y.; Chu, G.; Wang, J.; Huang, Y.; Chen, J.; Sun, B.; Shao, L. Controllable preparation of nano-CaCO 3 in a microporous tube-in-tube microchannel reactor. Chem. Eng. Process. 2014, 79, 34-39. [CrossRef]

39. Li, S.; Xu, H.; Wang, Y.; Luo, G. Controllable preparation of nanoparticles by drops and plugs flow in a microchannel device. Langmuir 2008, 24, 4194-4199. [CrossRef] [PubMed]

40. Li, J.; Le, D.; Ferguson, P.P.; Dahn, J.R. Lithium polyacrylate as a binder for tin-cobalt-carbon negative electrodes in lithium-ion batteries. Electrochim. Acta 2010, 55, 2991-2995. [CrossRef]

41. Sun, Y.; Hu, X.; Luo, W.; Huang, Y. Porous carbon-modified MnO disks prepared by a microwave-polyol process and their superior lithium-ion storage properties. J. Mater. Chem. 2012, 22, 19190-19195. [CrossRef]

42. Sun, X.; Xu, Y.; Ding, P.; Chen, G.; Zheng, X. Superior lithium storage of the carbon modified hybrid of manganese monoxide and carbon nanotubes. Mater. Lett. 2013, 113, 186-189. [CrossRef] 
43. Sun, X.; Xu, Y.; Ding, P.; Jia, M.; Ceder, G. The composite rods of MnO and multi-walled carbon nanotubes as anode materials for lithium ion batteries. J. Power Sources 2013, 244, 690-694. [CrossRef]

44. Zhao, C.; He, L.; Qiao, S.Z.; Middelberg, A.P.J. Nanoparticle synthesis in microreactors. Chem. Eng. Sci. 2011, 66, 1463-1479. [CrossRef]

45. Ying, Y.; Chen, G.; Zhao, Y.; Li, S.; Yuan, Q. A high throughput methodology for continuous preparation of monodispersed nanocrystals in microfluidic reactors. Chem. Eng. J. 2008, 135, 209-215. [CrossRef]

46. Luo, W.; Hu, X.; Sun, Y.; Huang, Y. Controlled Synthesis of Mesoporous MnO/C Networks by Microwave Irradiation and Their Enhanced Lithium-Storage Properties. ACS Appl. Mater. Interfaces 2013, 5, 1997-2003. [CrossRef] [PubMed]

47. Wang, T.; Peng, Z.; Wang, Y.; Tang, J.; Zheng, G. MnO Nanoparticle@Mesoporous Carbon Composites Grown on Conducting Substrates Featuring High-performance Lithium-ion Battery, Supercapacitor and Sensor. Sci. Rep. 2013, 3, 2693. [CrossRef] [PubMed]

48. Su, K.; Wang, C.; Nie, H.; Guan, Y.; Liu, F.; Chen, J. Facile template-free synthesis of 3D porous MnO/C microspheres with controllable pore size for high-performance lithium-ion battery anodes. J. Mater. Chem. A 2014, 2, 10000-10006. [CrossRef]

49. Zhang, J.; Yang, X.; Wang, R.; Dong, W.; Lu, W.; Wu, X.; Wang, X.; Li, H.; Chen, L. Influences of Additives on the Formation of a Solid Electrolyte Interphase on MnO Electrode Studied by Atomic Force Microscopy and Force Spectroscopy. J. Phys. Chem. C 2014, 118, 20756-20762. [CrossRef]

50. Tao, X.; Chai, W.; Xu, F.; Luo, J.; Xiao, H.; Liang, C.; Gan, Y.; Huang, H.; Xia, Y.; Zhang, W. Bio-templated Fabrication of Highly Defective Carbon Anchored MnO Anode Materials with High Reversible Capacity. Electrochim. Acta 2015, 169, 159-167. [CrossRef]

51. Wang, S.; Xiao, C.; Xing, Y.; Xu, H.; Zhang, S. Formation of a stable carbon framework in a MnO yolk-shell sphere to achieve exceptional performance for a Li-ion battery anode. J. Mater. Chem. A 2015, 3, 15591-15597. [CrossRef]

52. Sun, B.; Chen, Z.; Kim, H.; Ahn, H.; Wang, G. MnO/C core-shell nanorods as high capacity anode materials for lithium-ion batteries. J. Power Sources 2011, 196, 3346-3349. [CrossRef]

53. Xu, S.; Zhu, Y.; Zhuang, Q.; Wu, C. Hydrothermal synthesis of manganese oxides/carbon nanotubes composites as anode materials for lithium ion batteries. Mater. Res. Bull. 2013, 48, 3479-3484. [CrossRef] 